\title{
Making the difference in education: History of science providing better understanding of some current issues of medical education and practice: a brief report on the controversies about evidence-based medicine
}

\author{
Tânia Guimarães Lapa', Marcelo Nunes Dourado Rocha², \\ Naomar Monteiro Almeida Filho ${ }^{3}$, André Luis Mattedi Dias ${ }^{4}$ \\ ${ }^{1}$ Corresponding author. Federal University of Recôncavo da Bahia, Federal University of Bahia. Santo Antônio de Jesus/Salvador, Bahia, Brazil. \\ ORCID: 0000-0003-4847-5868. tanialapapc@gmail.com \\ ${ }^{2}$ Federal University of Bahia. Salvador, Bahia, Brazil. ORCID: 0000-0001-8766-3939. mndrocha@gmail.com \\ ${ }^{3}$ Federal University of Bahia. Salvador, Bahia, Brazil. ORCID: 0000-0002-4435-755X. naomaralmeida@gmail.com \\ ${ }^{4}$ Federal University of Bahia. Salvador, Bahia, Brazil. ORCID: 0000-0002-3943-0951. andre.mattedi@ufba.br
}

ABSTRACT | BACKGROUND: A usual question from pediatrics emergence in public hospitals leads to evidence-based medicine (EBM), a new paradigm for medical education and practice. However, although canonical texts have presented EBM apologetically, a lot of criticism has resulted in controversy involving its supporters and opponents. OBJECTIVES: To provide a better understanding of EBM based on historical analyses of its controversies. METHODS: Historical analysis of controversies about EBM. MATERIALS: Primary and secondary sources on EBM from international medical journals. Results: The hierarchy of evidence that forms the epistemic basis of EBM has been strongly contested by its opponents; the interest and involvement of biomedical and pharmaceutical corporations on the trials has been denounced; as well as the prevalence of algorithmic approaches instead of comprehensive and humanized forms of care, with the consequent loss of the physician's professional autonomy and their submission to protocols. CONCLUSIONS: EBM is much more than rational and objective search, evaluation and clinical application of the "best" scientific evidence published in medical journals. A better understanding of its historical, epistemic, ethical, political and social aspects and dimensions allow us to balance the impact of prevailing technoscientific influences on medical education and clinical practice.

KEYWORDS: Medical education. Evidence-based medicine. History. Clinical practice. 
From searching for the best scientific evidence...

When attending pediatric emergence in two public hospitals of Salvador, imaging procedures eventually can raise some difficulties if there is not an anesthesiologist available to perform children sedation, because those hospitals have not yet prescribed a preferential drug for use when pediatricians have to perform the sedation.

Currently the search for an answer to this question leads to systematic reviews (SR) and evidence-based medicine (EBM). SR is a statistics based methodology widely employed for search and evaluation of "best" published scientific evidence for the purpose of contributing to solving clinical practice problems. SR stands in the main core of EBM that David Sacket and his team of McMaster University presented as a new paradigm for medical education and practice. They rejected individual clinical experience and pathophysiological reasoning as sufficient epistemological basis for clinical decision making and claimed that physicians should be trained in biostatistics and clinical epidemiology to develop the necessary skills to apply scientific criteria on clinical judgments. According to EBM, medical education should be renewed to integrate the ability to analyze and rationally apply scientific information in clinical practice, to improve health practices according to the best scientific evidence, supporting the development of protocols for the clinical management of the patients ${ }^{1,5}$.

\section{... to finding controversies on EBM}

However, although canonical texts have presented EBM apologetically, opponents addressed criticisms against EBM that raised many controversies with its founders. Indeed, we analyzed many controversies about EBM that have occurred in scientific medical journals from the 1990s to the present day, and noticed many strong reactions against $\mathrm{EBM}^{6}$. In addition to epistemic, logical and methodological problems, ethical issues involving political and social implications have been raised. In short, the hierarchy of evidence that forms the epistemic basis of EBM has been strongly contested; the interest and involvement of biomedical and pharmaceutical corporations on the trials have been denounced; as well as the prevalence of algorithmic approaches instead of comprehensive and humanized forms of care, with the consequent loss of physician's professional autonomy and their submission to protocols ${ }^{7,15}$.

\section{History of Science providing tools...}

Thomas Kuhn's concepts of normal and paradigmatic science have been useful to us in order to better understand the apologetic approach adopted by founders and adepts of EBM, mainly in handbooks and tutorials intended for beginners. According to Kuhn, normal science is driven by adherence to a paradigm that supply scientists with model-problems to solve and tools for its solutions. Therefore, the role of science textbooks is to exhibit this sort of problems and its solutions and then to ask the student to solve similar ones for himself ${ }^{16}$. That's what a beginner usually finds when tries its first steps following EBM handbooks and tutorials ${ }^{5}$ : ask a question, search the best evidence, evaluate and apply it to clinical practice. Summing up, beginners around the world usually associate EBM with doing SR in a rational and objective fashion ${ }^{17,18}$.

As is well known, Thomas Kuhn's seminal work paved the way for a radical critical review of the traditional empiricist concept of science, which has been adopted by EBM founders. New approaches in history, sociology and philosophy of science that developed since the 1970's have recognized how controversy plays a constitutive role in the development of scientific knowledge and is an epistemological relevant factor beside facts, logic and methodology. Furthermore science is no longer regarded as a logical and methodological ideal game between objective hypothesis and absolute evidence ruled by a neutral judge, but a sociocultural process that actual scientists participate with their concrete interests and values, belonging to their social and cultural environment. Yet the goal of the analyses of scientific controversy is to highlight these sociocultural dimensions and aspects of the scientific practice and development ${ }^{19,21}$. 


\section{its limitations}

After analyzing that controversies about EBM, we could understand that the new "paradigm" presented by EBM founders entails much more than rational and objective search and clinical application of the "best" scientific evidence from RCTs reports published in the most prestigious scientific journals, systematically reviewed according to the most rigorous statistical theories. Indeed there are some very important aspects, dimensions and processes within EBM which are not usually highlighted by its canonical texts and not immediately perceived by physicians in general. A broader, more complex and richer landscape emerges beyond that instrumental and dogmatic view designed in textbooks and tutorials. Paying attention to historical, epistemic, ethical, political and social aspects and dimensions that constitute EBM, we are now able to balance the prevailing influences of technoscientific concepts and methods and their impact not only on medicine but also on university medical education and the wider field of health.

Notwithstanding EBM defenders have been claiming that medical education should broaden and deepen curriculum scientific features, on the other hand, EBM opponents have been claiming that, at least, humanistic and sociopolitical add-ons must balance scientism, providing reflections on the limits of scientific methods and techniques, valuing human beings integrity, humans preferences and values, social relationships, culture, spirituality, concerns, fears and other emotions.

In short, a deep and richer view of EBM empowers physicians humanistic understanding that patient care and public health policy demand value decisions that cannot be reduced to the alleged factual objectivity of scientific experimentation. Better health care and social justice can be provided for all only if technoscientific knowledge and procedures are adopted on the basis of appropriate ethical precautions.
Lapa TG is the first author of the article which is an extract from her thesis. Rocha MD supervised the research. Almeida N was coadvisor of the thesis, contributing mainly, but not exclusively, to the aspects of work related to Evidence-Based Medicine, including his vision as a model of contemporary education in the health sciences field. Mattedi A contributed to the methodological aspects related to the history of scientific controversies.

\section{Competing interests}

No financial, legal or political competing interests with third parties (government, commercial, private foundation, etc.) were disclosed for any aspect of the submitted work (including but not limited to grants, data monitoring board, study design, manuscript preparation, statistical analysis, etc.).

\section{References}

1. Guyatt GH. Editorial: Evidence-based medicine. ACP J Club. 1991;114(2):A16. doi: 10.7326/ACPJC-1991-114-2-A16

2. Guyatt G, Cairns J, Churchill D, Cook D, Haynes B, Hirsh J, et al. Evidence-Based Medicine: A New Approach to Teaching the Practice of Medicine. JAMA. 1992;268(17):2420-5. doi: $10.1001 /$ jama.1992.03490170092032

3. Sackett $D L$, Rosenberg WMC. On the need for evidence-based medicine. J R Soc Med. 1995;88(11):620-4.

4. Sackett DL, Rosenberg WM, Gray JA, Haynes RB, Richardson WS. Evidence based medicine: what it is and what it isn't. BMJ. 1996;312(7023):71-2. doi: 10.1136/bmj.312.7023.71

5. Sackett DL, Straus SE, Richardson WS, Rosemberg W, Haynes $\mathrm{RB}$, editors. Evidence-based medicine: how to practice and teach EBM. Edinburgh: Churchill Livingstone; 1997. 261 p.

6. Cohen AM, Stavri PZ, Hersh WR. A categorization and analysis of the criticisms of Evidence-Based Medicine. Int J Med Inf. 2004;73(1):35-43. doi: 10.1016/j.ijmedinf.2003.11.002

7. Editorial. Evidence-based medicine, in its place. The Lancet. 1995;346(8978):785.

8. Tonelli MR. The philosophical limits of evidence-based medicine. Acad Med J Assoc Am Med Coll. 1998;73(12):1234-40. doi: $10.1097 / 00001888-199812000-00011$ 
10. Meulen R ter, Dickenson DL. Into the hidden world behind evidence-based medicine. Health Care Anal. 2002;10(3):231-41.

11. Loewy EH. Ethics and Evidence-Based Medicine: Is There a Conflict? Medscape Gen Med. 2007;9(3):30.

12. Miles A, editor. Special Issue: Evidence-based medicine. J Eval Clin Pract. 1996;2(1). doi: 10.1111/j.1365-2753.2009.01353.x

13. Wyer PC, Silva SA. Where is the wisdom? I - a conceptual history of evidence-based medicine. J Eval Clin Pract.

2009;15(6):891-8. doi: 10.1111/j.1365-2753.2009.01323.x

14. Marck MA, Melis RJF, Rikkert MGMO. On evidence-based medicine. The Lancet. 2017;390(10109):2244-5. doi: 10.1016/ s0140-6736(17)32851-9

15. Mercuri M, Gafni A. The evolution of GRADE (part 3): A framework built on science or faith? J Eval Clin Pract. 2018;24(5):1223-31. doi: 10.1111/jep.13016

16. Kuhn TS. The function of dogma in scientific research. In: Crombie AC, editor. Scientific Change. London: Heinemann; 1963. p. 347-69.

17. Blanco MA, Capello CF, Dorsch JL, Perry G (Jerry), Zanetti ML. A survey study of evidence-based medicine training in US and Canadian medical schools. J Med Libr Assoc JMLA. 2014;102(3):160-8. doi: 10.3163/1536-5050.102.3.005

18. Meats E, Heneghan C, Crilly M, Glasziou P. Evidencebased medicine teaching in UK medical schools. Med Teach. 2009;31(4):369-74. doi: 10.1080/01421590802572791

19. Pinch T. Scientific Controversies. In: Smelser NJ, Baltes PB, editors. International Encyclopedia of the Social \& Behavioral Sciences. Oxford: Pergamon; 2001. p. 13719-24.

20. Machamer PK, Pera M, Baltas A, editors. Scientific controversies: philosophical and historical perspectives. New York: Oxford University Press; 2000. p. 278.

21. Pestre D. Pour une histoire sociale et culturelle des sciences. Nouvelles définitions, nouveaux objets, nouvelles pratiques. Annales. 1995;50(3):487-522. 